\title{
BINARY STAR ASTROMETRY WITH THE HUBBLE SPACE TELESCOPE: ONE MILLISECOND OF ARC ACCURACY AND BEYOND
}

\author{
O. FRANZ, K.J. KREIDL, L.H. WASSERMAN, \\ A.J. BRADLEY, G.F. BENEDICT, R.L. DUNCOMBE, \\ P.D. HEMENWAY, W.H. JEFFERYS, B. McARTHUR, \\ E. NELAN, P.J. SHELUS, D. STORY, \\ A.L. WHIPPLE, L.W. FREDRICK and W.F. van ALTENA
}

\begin{abstract}
We briefly review the concept of double star measurement with HST Fine Guidance Sensors (FGS) in the Transfer Function (TF) Scan mode and give results for three calibration binaries observed with FGS3. Agreement among multiple observations indicates an astrometric precision of 1 millisecond of arc (mas) per observation. We compare measured angular separations with ephemeris values from orbits based entirely on speckle observations. This comparison shows that the accuracy of binary-star astrometry with FGS3 in the TF-Scan mode is 1 mas per observation. Multiple observations can be expected to produce relative positions of binary components at sub-millisecond of arc accuracy.
\end{abstract}

